\title{
Advanced Practice Nursing in Nigerian Healthcare: Prospects and Challenges
}

\author{
Raymond O. Chimezie \\ University of San Francisco \\ Sally N. Ibe \\ Federal University of Technology
}

\begin{abstract}
This study explored the prospects and challenges of introducing advanced practice nursing (APN) in the Nigerian health system. It sought to address the following: career pathways for registered nurses and midwives, advanced duties performed by them and the circumstances, their views and willingness for autonomous practice, and doctors' degree of acceptance.

Research population composed of registered nurses, midwives and medical doctors in primary healthcare. The conceptual framework for this study was based on the scope of practice, standards and competencies of the APN established by the International Council of Nurses (2008). A 12-item checklist of typical duties of APN from the framework provided a guide for the design of eight main questions and 19 subquestions. Data was collected from 17 participants through in-depth interviews and group discussions and analyzed using Charmaz's three simplified methods for qualitative data. Findings were that (a) registered nurses and midwives are constrained to perform advanced duties, (b) doctors delegate advanced roles to nurses and midwives, (c) nurses and midwives lacked pathways for advancement, (d) APN would substitute for doctor shortage, and (e) advocacy and lobbying has to done by the Nursing and Midwifery Council of Nigeria to change the current policy. The social change implication is that it offers insight into the potentials for APN in healthcare delivery.
\end{abstract}

Keywords: advanced practice nursing, advanced nursing, nursing education in Nigeria, healthcare in Nigeria, health workforce development, primary healthcare in Nigeria

\section{Introduction}

\section{Background}

Nigeria's three-tier health system is managed in accordance with the three tiers of government: the local (primary), state (secondary), and federal (tertiary). The primary healthcare under the local government is the most neglected and poorest managed of the health system due to the poor administrative structure of the local government system. Primary healthcare is the bedrock of any health system because it caters to the health needs of the poor and rural population. The persistent underperformance of the Nigerian health system, especially at the primary healthcare level, has seriously affected health, wellness, and lifespan of Nigerians. Nigeria accounts for $27 \%$ of global malarial cases (World Health Organization, 2017) and is ranked as having the worst health indicators in Africa (United States Agency for International Development, 2019). According to the U.S. Central Intelligence Agency's (2019) World Factbook, Nigeria has more than 200 million people,

We acknowledge contributions from all participants, the Center for Research and International Development, students and faculty of the Department of Public Health at the Federal University of Technology in Owerri, Nigeria, and the Fulbright Program for financial support. 
$49 \%$ of whom live in rural areas; a life expectancy of 57.5 and 61 years for men and women, respectively; high maternal and infant mortality rates; high infectious disease risks; and 1.9 million people living with HIV/AIDS. These data are troubling and demand that Nigeria looks for sustainable evidence-based strategies to address its ongoing health crisis.

The underperformance of the Nigerian health system is caused by many factors. Among these factors are that Nigeria allocates only $3.65 \%$ of its national budget to healthcare as opposed to the recommended 15\% (World Bank 2019; World Health Organization, 2011), its systemic inequity in resource allocation and health workforce distribution between rural and urban health facilities (Okpani \& Abimbola, 2015), a dysfunctional primary healthcare system (Welcome, 2011) and a weak administrative structure of the local government which manages primary healthcare delivery (Chimezie, 2013). Also, the Nigeria health system is fundamentally deficient because it was inherited from the British colonial government and not planned from the bottom up to respond to Nigeria's health needs. Discriminative as it was, it catered far more to the health needs of the colonial masters and their staffers in the urban areas than to the more vulnerable rural population. Also, the Biafra-Nigeria Civil War of 1967-1970 helped destroy many rural infrastructures including health centers. In the 1970s and 1980s, Nigeria had through national planning attempted to implement a people-centered social change that would improve rural infrastructure and fix its broken health system. For instance, Nigeria had initiated a strong welfare policy to promote employment and job security and foster better public-sector-driven economy or government-initiated and managed enterprises (Ekanade, 2014; Odili, 2019; Olorode, 2016).

Before any of the anticipated social change could take place, Nigeria was coerced by the West to adopt neoliberalism in the 1980s. Neoliberalism, a sociopolitical agenda of the West for global economic dominance, forced the Nigerian government to relinquish its people-centered social and economic responsibilities to market forces (Ekanade, 2014; Odili, 2019; Olorode, 2016). The implementation of the neoliberal socioeconomic agenda compelled Nigeria to abandon its peoplecentered policy and instead adopt the Structural Adjustment Program (SAP) to promote trade liberalization, free market, privatization of public enterprises, reduce public sector expenditure, and so forth. Unfortunately, these socioeconomic adjustments and policies couldn't deliver the expected outcomes for sustainable economic growth. Instead, they resulted in the government withdrawal of subsidies from essential public services, wage cuts and embargo on employment (Ekanade, 2014; Nwagbara, 2011). The results were overall infrastructural decay, mass unemployment, and decline in quality of life. The absence of essential amenities and poor health infrastructure discouraged qualified doctors from accepting work in rural health facilities.

Consequently, primary healthcare delivery fell on the shoulders of registered nurses and midwives whose skills sets and competences were inadequate to qualify as primary healthcare providers (Chimezie, 2013, 2015). Without qualified doctors at primary health centers, registered nurses and midwives were faced with compelling circumstances and were overstretched to perform duties beyond their licensure to respond to population health needs. Misdiagnosis, death, and disease complications are possible under such situations.

\section{Meaning and Basis for Advanced Practice Nursing}

According to the International Council of Nurses Nurse Practitioner (NP)/Advanced Practice Nursing (APN) Network (2019), 
A Nurse Practitioner/Advanced Practice Nurse is a registered nurse who has acquired the expert knowledge base, complex decision-making skills and clinical competencies for expanded practice, the characteristics of which are shaped by the context and/or country in which s/he is credentialed to practice. A master's degree is recommended for entry level. (para 2)

Also, the Royal College of General Practitioners (2015) defined APNs as experienced and autonomous registered nurses who have developed and extended their practice and skills beyond their previous professional boundaries. Characteristically, APNs are self-directed, work beyond their initial registration, and engage in direct clinical practice, education, research, and management. Their titles and roles (Sheer, Kam, \& Wong, 2008) vary according to country needs: NP in the United States, United Kingdom, Canada, and New Zealand or APN in China, South Africa, Korea, Singapore, Hong Kong, Thailand, Australia, and Finland.

\section{Literature Review}

Various articles were reviewed from Academic Search Premier, online scholarly journals, reports, and open access databases. The search terms used included nursing practice, advanced practice nursing, prospects and challenges to advanced nursing practice, and nursing practice in healthcare delivery. APN roles and inclusion in the mainstream health delivery are growing globally, but APN's recognition and introduction in the health system are still very slow and at the rudimentary level in Nigeria and other Sub-Saharan African countries (East, Arudo, Loefler \& Evans, 2014; Fox-Mcloy, 2014). In Nigeria and many African countries, the great potentials for APNs as qualified primary health providers in the health system have yet to be explored, developed, and used. Pulcini, Jelic, Gul, and Loke (2010) described NPs and APNs as "a sleeping giant for healthcare systems worldwide, particularly in developing countries, to meet the need for increased access to quality health care" (p. 37). Also, the former coordinator of nursing affairs for the West African College of Nursing, Grace Madubuko (n.d), stated,

The goal is to produce advanced nurse practitioners with the expanded scope of practice who are able to meet the health needs of individuals, families, groups, populations or entire communities and contributing to nursing knowledge and advancing nursing profession in West Africa. (p. 2)

\section{Drivers for Advanced Practice Nursing in Healthcare}

Evidence from literature showed that expanding the traditional role of registered nurses and midwives in healthcare delivery improved patients' health access and satisfaction, reduced wait time (Colombo, 2016), reduced doctor shortage in healthcare delivery (Sibbald, Laurant, \& Reeves, 2006), cut healthcare costs and wait time (Sheer et al., 2008; De Geesta et al., 2008), and provided care comparable to or better than physicians in ambulatory care settings (Naylor \& Kurtzman, 2010). Accordingly, the U.S. Institute of Medicine (2010) recommended that transforming the healthcare system to meet the demand for safe, quality, and affordable care will require a fundamental rethinking of the roles of many healthcare professionals, including nurses. It further stated that nurses are well positioned to help meet the evolving needs of the healthcare system and have vital roles to play in achieving patient-centered care, strengthening primary care services, delivering more care in the community, and providing seamless coordinated care. 
APN has been gaining global attention. In the United States, there are over 205,000 licensed NPs providing various relevant healthcare services as of 2015 (Health Resources \& Services Administration, 2015). According to Kaiser Family Foundation (2015), as of 2015, 33 U.S. states granted NPs autonomy to diagnose and treat patients without physician involvement; 10 states had a NP-Physician collaborative agreement, and eight required NPs to be supervised by doctors. Also, in Canada, APN was introduced to respond to the health needs of the public, and the number of NPs has grown tremendously from 1,669 in 2008 to 5,274 in 2017 (Canadian Institute for Health Information, 2017). APNs enjoy great autonomy in New Zealand, including assessment, diagnosis, ordering, and interpreting diagnostic laboratory tests; administering treatments/therapies; and admitting and discharging from hospitals (New Zealand Ministry of Health, 2017). NPs were introduced in Korea since the 1950s, Taiwan in 1994, and in Thailand in 2004 (Sheer \& Wong, 2008).

\section{Present Study}

\section{Statement of Problem}

Nigerians experience increasing mortality and morbidity from preventable causes due to their inability to consult a qualified doctor when sick. Nigeria does not produce enough physicians, but has abundant nurses and midwives whose skills can be expanded to perform some advanced duties. Also many doctors migrate overseas for better opportunities or refuse jobs in rural areas because of the dysfunctional health system.

\section{Nature of Study}

This qualitative study used focus group discussions and key informant interviews of 17 purposefully selected participants (12 registered nurses and midwives and five medical doctors) to explore the prospects and challenges of APN in the Nigerian health system. This sample size was considered adequate because a larger sample size would be cumbersome to extract relevant data, whereas a thin sample size would make it hard to achieve data saturation (Onwuegbuzie \& Leech, 2007). Purposive sampling was used because the researchers believed that the education and experiences of the participants would be relevant to the phenomenon under investigation (Babbie, 2016; Creswell \& Cheryl, 2016). The researchers assumed that participants are aware of the impact of a doctor shortage to patients' health outcomes.

\section{Significance of the Study}

This study offers insight and information as to the potential for social change through a more liberalized nursing and midwifery practice by scaling the profession into more advanced roles. It introduces an option to develop a sustainable and cost-beneficial option for alternative health workforce to remedy the doctor shortage in primary healthcare delivery.

\section{Research Design and Conceptual Framework}

The conceptual framework for this study was based on the scope of practice, standards and competencies of the APN established by the International Council of Nurses (2008). The framework recommends that competencies of the generalist nurse can be developed by allowing for the supplementation of new competencies that reflect an expanding level of practice. It emphasized the importance of developing advanced practice through higher education, which prepares the nurse with skills and experience critical to analyze a problem and make good judgement in delivering 
nurse-patient-centered care. The framework helps to position nurses and midwives for future health needs, and create pathways for lifelong learning and career development. It differentiates the roles of the APN from that of the generalist nurse by stating 12 -item basic professional duties of APNs that were used in the development of the questionnaires for this study. Nine registered nurses and midwives and five medical doctors were in the focus group discussion; three registered nurses and midwives were engaged as key informants. Eight overarching questions and 19 subquestions were asked of participants.

\section{For Registered Nurses and Midwives}

Research Question 1: Where do you see yourself in the next 10 years in your career? (a) How do you intend to accomplish that? (b) Do you see any obstacles to that goal?

Research Question 2: As a nurse/midwife, have you performed any roles higher than what you should normally do? (a) What were they? (b) Describe them. (c) Why did you do them? (Reference the APN framework). (d) How did you learn the skills?

Research Question 3: Should registered nurses/midwives be allowed to some advanced roles to reduce doctor shortage in health delivery? (a) What roles and why?

Research Question 4: APN would give nurses/midwives autonomy to diagnose diseases, write prescriptions, order laboratory tests, etc., with or without doctor supervision. (a) Do you see any prospects? (b) Do you see any challenges? (c) Suggest solutions.

\section{For Medical Doctors}

Research Question 5: What are the typical roles of a nurse/midwife working under you? (a) Are any of the roles extraordinary?

Research Question 6: Describe specific higher duties a nurse/midwife performed under you. (a) Have you assigned such a role to nurse/midwife before? (b) Has a nurse/midwife assisted you with skills and knowledge when performing advanced skills? (c) Ever covered your shift? (d) Ever trained them for higher duties? If yes, why? If no, how did they acquire the skills?

Research Question 7: Do you support nurses/midwives to perform advanced care delivery to remedy the shortage of medical doctors in health delivery? (a) What are your reasons?

Research Question 8: APN would give nurses/midwives autonomy to diagnose diseases, write prescriptions, order laboratory tests, etc., with or without doctor supervision. (a) Do you see any prospects? (b) Do you see any challenges? (c) Suggest solutions.

\section{Method}

\section{Purpose}

The purposes of this study were (a) to conduct focus group discussions with doctors and registered nurses and midwives about advancing the role of registered nurses and midwives in primary healthcare delivery with authorization to diagnose, prescribe, treat, and manage patients and (b) to determine any challenges to APN in Nigeria. 


\section{Setting}

The study was set in Imo State, Nigeria, a rural area with a population of over 5 million people (Imo State Government, 2019). Imo consists of vast flat areas suitable for farming and maintaining a variety of trees indigenous to the area (e.g., palms, irokos, coconuts, raffia, bamboo). Erosion is common in the months of April to October, which causes damage to roads, wears away soil nutrients, and contaminates wells and streams (Amangabara, 2012) - all of which provide breeding grounds for mosquitos.

\section{Participants and Recruitment}

All nurses and midwives in this study had current registration with the Nursing and Midwifery Council of Nigeria (NMCN) and the doctors were registered with the Medical and Dental Council of Nigeria (see Table 1) The perceptions of registered nurses and midwives are valuable to determine what advanced duties they do, the prospects and challenges to APN in the health system. The views of doctors are equally significant to determine their receptivity or extent thereof for introducing APN in the health system.

Table 1. Participant Demographics

\begin{tabular}{|c|c|c|c|c|}
\hline Participant & Gender & $\begin{array}{l}\text { Experience, } \\
\text { Years }\end{array}$ & Job Setting & Qualifications \\
\hline \multicolumn{5}{|c|}{ Registered nurses and midwives } \\
\hline Participant 1 & Female & 26 & Public & BS Nursing, RN, RM \\
\hline Participant 2 & Female & 16 & Public & $\begin{array}{c}\text { BEd (Health Education), RN, RM, } \\
\text { MPH, PGD }\end{array}$ \\
\hline Participant 3 & Female & 22 & Public & $\begin{array}{l}\text { National Registered Nurse and } \\
\text { Midwife, } \\
\text { BS Nutrition and Dietetics, MS } \\
\text { (student) }\end{array}$ \\
\hline Participant 4 & Female & 10 & Public & BNSc, RM, RN \\
\hline Participant 5 & Female & 10 & Public & $\mathrm{BNSc}, \mathrm{RN}, \mathrm{RM}$ \\
\hline Participant 6 & Female & 10 & Public & BNSc, RN, RM \\
\hline Participant 7 & Female & 7 & Public & $\mathrm{RM}, \mathrm{RN}$ \\
\hline Participant 8 & Female & 10 & Public & $\mathrm{RN}, \mathrm{RM}$ \\
\hline Participant 9 & Female & 25 & Public & $\mathrm{RN}, \mathrm{RM}$ \\
\hline Participant 10 & Female & 7 & Public & CHEW, RM \\
\hline Participant 11 & Female & 24 & Public & RM, RN, BS, MBA, MS, MS Nursing \\
\hline Participant 12 & Female & 9 & Public & CHEW, RM \\
\hline \multicolumn{5}{|l|}{ Medical doctors } \\
\hline Participant 13 & Male & 34 & Public & MBBS \\
\hline Participant 14 & Male & 37 & Private & MD \\
\hline Participant 15 & Female & 32 & Public & MBBS \\
\hline Participant 16 & Male & 20 & Public/Private & MBBS \\
\hline Participant 17 & Male & 17 & Private/Public & MBBS \\
\hline
\end{tabular}

Note. $\mathrm{BS}=$ Bachelor of Science; $\mathrm{RN}=$ Registered Nurse; RM = Registered Midwife; BEd = Bachelor of Education; $\mathrm{MPH}=$ Master of Public Health; PGD = postgraduate diploma; BNSc = Bachelor of Nursing Science; MS = Master of Science; CHEW = Community Health Extension Worker; MBA = Master of Business Administration; MBBS $=$ Bachelor of Medicine, Bachelor of Surgery; MD = Doctor of Medicine. 


\section{Data Collection}

Data were collected through focus group discussions and key informant interviews with doctors, and registered nurses and midwives in primary health delivery. Ethical consideration and approval was granted by the Center for Research and International Development at the Federal University of Technology in Owerri, Nigeria. This research was funded in part by the 2016-2017 Fulbright Scholar award for Sub-Saharan Africa to Dr. Raymond Chimezie.

\section{Results}

To interpret data for this study, Charmaz's (2006) three-phase qualitative interview analysis was used. Phase 1 involved initial coding, in which researchers read participants' responses line by line to interact with and understand participants' standpoints, make sense of data, and code them. Phase 2 involved selective coding, during which researchers used repeating initial codes to sort and synthesize data. Finally, Phase 3 involved the development of codes or categories and analytic frameworks from the focused codes.

For Research Questions 1 and 5, respectively, registered nurses and midwives described their current and past job responsibilities and prospects and doctors described typical nurse and midwife roles under them. These questions carefully explored the actual duties of nurses and midwives in the health system and any convergence with advanced practices. Research Questions 2 and 6 explored advanced duties performed by nurses and midwives whether working alone or with a doctor, as well as the views of doctors on some of the "doctor procedures" successfully performed by nurses and midwives (either voluntarily or as assigned by a doctor). Through Research Questions 3 and 7, the researchers explored the future role of nurses and midwives from the viewpoints of doctors and nurses and midwives regarding current shortage of doctors in health system. Questions 4 and 8 explored the prospects and obstacles to APN in Nigeria. A review of responses from participants by the researchers yielded 23 codes; selective coding and synthesizing, which yielded similar or duplicate data, reduced the codes to 17. After further analysis, the researchers identified the following core themes about introducing APN in Nigeria: (a) limited career pathways and low recognition for registered nurses and midwives, (b) nurses' and midwives' desires for higher responsibilities, (c) nurses and midwives as complements to or substitutes for doctors, (d) contexts that motivated nurses and midwives to perform higher duties, (e) prospects for and challenges to introducing APN in Nigeria.

\section{Limited Career Pathways and Low Recognition for Registered Nurses and Midwives}

Many participants saw no visible career pathway in the profession and lamented on the lack of recognition for their efforts and impacts in the health system. Participant 10 said,

What I will do in the future depends on what the leaders of the nursing profession want and not based on my performance! Nurses have and continued to play significant roles in healthcare delivery, yet they are looked down upon when compared to other members of the health care team.

Participant 9 also expressed this uncertainty and frustration: "We are frustrated and benched by doctors who think that our growth will challenge them. We lack a visible pathway for growth and advancement."

Also, Participant 5 added, 
Nursing in Nigeria is regarded as women profession and so not attractive to most men. Medical laboratory science which is a newer profession has more recognition and career pathways than nursing and midwifery because it is dominated by men" All nurses and midwives agreed to this.

Other concerns expressed by nurses and midwives included lack of reimbursement for tuition, disregard for their initial professional license by universities in undergraduate admissions, poor remuneration, and noninvolvement in health or professional policy decisions (as expressed by Participants 4, 6, 8, 9, and 10). All nurses and midwives lamented that the health system is built around doctor practice to the disregard of their professional competencies and advancement. Participant 3 put it succinctly: "In the health system, nurses are the underdogs, always being referred to as 'other' while doctors, pharmacists, radiologist, and laboratory scientists are mention by their professional names." In view of these concerns, some nurses seek advanced degrees in other allied disciplines that are not nursing, whereas those who remain begin to develop poor patient relationships.

\section{Nurses' and Midwives' Desire for Higher Responsibilities in Health Delivery}

Registered nurses and midwives in Nigeria are aware of the transformative changes in the profession that come from advanced education. They know that nursing roles have changed in many advanced countries in response to increasing population health needs. Therefore, to remain relevant and contribute meaningfully, they want opportunities to move from bedside generalist nurse to APN. Participants 3 and 7 demanded that the health system be reformed and their scope of practice expanded to responsibilities such as direct patient care, autonomous practice, case management, research, leadership, and participation in policy decision-making. Participant 5 remarked, "I would like to extend health services to patients at home in order to ensure their full recovery and compliance with medications." Seven participants (66.7\%) agreed with this position for various reasons, such as bringing services to the homebound, improving access to care, reducing cost of care, supporting long-term care patients, and potentially changing roles other than being a bedside nurse. Doctors in the study shared the same view with nurses. Participants 14 and 15 said that nurses and midwives are important members of the healthcare team and that their roles in many cases complement the work of doctors. Participants 13 and 15 agreed that nurses and midwives are highly skilled and intelligent and that without them, some doctors could not function properly in a health setting. Participant 16, a doctor with 20 years of experienced, declared, "Nurses/midwives are invaluable members of the health team and should be availed more opportunities to advance their clinical or administrative skills to reach their potentials."

\section{Nurses and Midwives as Complements to or Substitutes for Doctors}

All study participants, agree that registered nurses and midwives in Nigeria do perform duties above their licensure to meet patients' health needs. Some agreed that nurses and midwives can perform better than some doctors if trained. For example, Participant 12 reported: "Nurses have diagnosed health problems, written prescriptions, and ordered laboratory tests." Doctors in the study confirmed that they have delegated or observed nurses and midwives in performing advanced duties in their practice to expedite patient care (Participants 13, 14, and 17). Participant 14 further explained, "Nurses/midwives have complemented my work some times when I was not available. And when I direct them to perform a higher tasks such writing prescriptions, lab referrals, and dressing wounds, and they do them very well." 
Participant 13 reported that nurses and midwives under him do catheterization, set intravenous lines, and manage children with high fever or convulsions: "They do it expertly." Participant 15 stated that most experienced and senior nurses and midwives do help doctors in most times of need, especially for new doctors. She recalled,

I was a house officer on-call in 1983; and just graduated from medical college. There was a mass casualty as a result of major road accident. I didn't know what to do! It was a nurse who directed me on what to do. She helped me survive the embarrassment that night. So, nurses can hold things for doctors and complement doctor shortage/lack of skill in health care. Nigerian nurses/midwives are very eager to learn some doctor procedures and can be very helpful in emergency situations.

\section{Contexts That Motivated Nurses and Midwives to Perform Higher Duties}

Patients' health needs are the main drivers for registered nurses and midwives who performed advanced care in the Nigerian health system. As the primary healthcare providers in most rural health centers, they are compelled to go above and beyond to save lives and reduce suffering. According to Participants 1, 2, 4, 7, and 9, nurses and midwives have, under compelling or emergency circumstances, to save lives, deliver babies, perform blood transfusions, suture wounds, and set up infusions and IV lines in their practice. Table 2 shows the extent to which they engaged in advanced healthcare practice. Participant 3 said,

At the primary health centers, there is no division of labor because you (nurse/midwife) are on your own and patients look up to you for their recovery and safety. There are too many expectations and mostly because you may be working among your relations or familiar community, you are pressured to do more.

Most nurse and midwife participants in this study had faced situations that demanded advanced practice skills to help patients. As Participant 2 described,

A patient with severe anemia (PVC [premature ventricular contraction] 15\%) was billed for blood transfusion. Blood was made available, but the house officers and resident doctors who were to administer the infusion were on strike. The consultant was notified via phone call. He directed me to administer the infusion without delay. With the help of another nurse, I transfused blood into the patient successfully and his condition improved. By this I saved a crisis situation.

As stated earlier, primary healthcare delivery falls under the jurisdiction of the local government administration. Local governments in Nigeria have weak administrative structure, lack proper oversight, are very poorly funded, and are unable to attract and retain qualified doctors to manage primary health centers. (Alenoghena, Aigbiremolen, Abejehah, Eboreime, 2014; Chimezie, 2013). Local governments in Nigeria do not get their funds or allocations directly from the federal government like state governments, but through the state governors. This has resulted in the misappropriation of funds meant for the local government by state governors, thereby crippling local governments' ability to meet local health needs. Under this situation, most local government primary health centers are managed by registered nurses and midwives, and community health extension workers. These categories of health workers have limited skills and education to run primary health facilities and to cater to both simple and complex health needs of the people. Typically, the scope of their duties include but are not limited to maternal and child care, immunizations, prevention and 
control of local endemics and epidemics, chronic health diseases, poison and snake bites, and dental, eye, and bone injuries. One participant described a compelling and challenging experience:

At the community health center, I work alone and do all duties. I oversee pregnant women from prenatal to postnatal care, deliver babies, perform circumcisions, manually remove placenta, write prescriptions, and teach health education. In some cases, I do episiotomy, pelvic assessment, augmentation of labor, and follow up with home visits to check on my patients. In certain cases, I performed cannulation on patients whenever no doctor is on-duty or directed by doctor to facilitate patient's care.

Participant 9 also shared an experience of performing higher duties in the absence of a doctor:

On some occasions when I was on night duty, some of the patients with diabetes mellitus showed signs and symptoms of hyperglycemia or hypoglycemia as the case may be. I quickly checked their blood glucose levels with glucometer and sent a call to the doctor-on-duty. When the patient's condition became critical and the doctor was not there, I gave insulin in the case of hyperglycemia and set up intravenous normal saline infusion. In the case of hypoglycemia, I gave glucose infusion.

\section{Prospects for and Challenges to Introducing Advanced Practice Nursing}

Participants saw the prospects of APN in the following ways: "to save the life of the patient in crisis" (Participant 2), "to assist doctors" (Participant 6), and "to staff rural health centers, and help in emergencies and in the absence of a doctor on site" (Participant 4). Registered nurses and midwives in Nigeria perceived APN as a sure pathway for profession growth and enhanced relevance as members of the healthcare team. As Participant 1 stated, "We need an enhanced authorization on our licenses to perform higher duties without fear or unnecessary query from doctors." Doctors supported APN as an alternative to no doctors at rural health centers. Participant 15 joked, "We need APNs so that the key would have a spare for the lock." That means APNs would be good substitutes to provide primary healthcare in the absence of qualified doctors at local health facilities.

Some doctors felt negatively about elevating nurses and midwives to APNs, finding it unfair to compare their 8 years in medical school with nurses' and midwives' 2 years of medical education. Participant 16 questioned, "Do all the nurses/midwives who treat and prescribe drugs to patients as they learned from doctors know about the drugs prescribed and all the side effects? Do they know that no two medical cases are exactly alike?"

Another challenge to elevating nurses and midwives to APNs was that the education was traditionally structured as trade skill and hospital based without academic curricular similar to programs in postsecondary higher institutions. Underscoring this deficiency, Participant 15, a doctor, remarked, "Current preliminary licensure in nursing/midwifery education lacked the core of medical practice education in microbiology and immunology, pathology, pharmacology, physiology, and medicine. Therefore, APNs should only have patients under doctor supervisions."

Nurses and midwives also raised strong concern about their professional body, the NMCN. They feared that the NMCN is not strong enough to make their case against anticipated agitation from the Nigerian Medical and Dental Council, which has the monopoly of authority in the health system. 
Table 2. Checklist of Higher Level Duties Performed by Nurses and Midwives in Nigeria

\begin{tabular}{lcc}
\hline Duty & $\boldsymbol{n}$ & $\mathbf{\%}$ \\
\hline Direct delivery of expert care to patients & 12 & 100 \\
Manage independent caseload & 12 & 100 \\
Direct advising of other health workers & 8 & 67 \\
Advocate for policy development & 2 & 16 \\
Teach colleagues and students in workplace & 9 & 75 \\
Teach formally in classroom & 2 & 16 \\
Spend time in the library & 4 & 32 \\
Collect data on service outcomes & 4 & 32 \\
Formulate protocols & 5 & 47 \\
Research as an investigator & 1 & 8 \\
Conducting research in a team & 2 & 16 \\
Administrate staff records & 11 & 91.6 \\
\hline
\end{tabular}

\section{Discussion}

This study was intended to explore the prospects and challenges of introducing APN to the Nigerian health system. Despite the fact that Nigeria has delegated primary healthcare to the local government and the presence of local health facilities, deaths and diseases from preventable causes are very common. One of the many problems is the absence of qualified medical doctors at the primary health facilities to manage patients' health needs (Chimezie, 2013). In view of this problem and its catastrophic consequences, it becomes necessary to examine the views of doctors, nurses, and midwives on the need for an alternative health workforce like APN to perform some advanced duties to minimize the health impacts of doctor shortage to population health. Data collected and analyzed in this study showed that APN would improve community access to health delivery, but current laws and professional jealousy from doctors pose challenges to its implementation. There is clear evidence that nurses and midwives in Nigeria are marginalized, lack opportunities for professional growth and advancement, are overstretched, are poorly rewarded, and are overshadowed by physicians. Despite this, patients' health needs and the shortage of doctors still motivate nurses and midwives to perform advanced care. Apart from nurses' and midwives' great compassion and commitments to patients' care, their desire for higher roles and remaining relevant to their patients motivates them to acquire advanced skills through self-study or by working alongside doctors. Evidently, another important driver for introducing the APN is that medical doctors sometimes delegate experienced nurses to perform more advanced duties—often without doctor supervision or oversight.

This study is only a preliminary look into the introduction of APN in the Nigerian health system. The views expressed in the study do not represent the opinions of all doctors, nurses, or midwives in Nigeria. The study instrument was self-designed and has not been tested anywhere as to produce the best result.

This study offers insight and information as to the potential for social change through a more liberalized nursing and midwifery practice by scaling the nursing and midwifery profession into more advanced roles. It introduces an option to develop a sustainable and cost-benefit alternative to the health workforce to remedy the doctor shortage in primary healthcare delivery. 


\section{Recommendations}

To remedy this, we recommend that the NMCN set up a national body for professional development and to champion a reform to change legislation in favor of APN. NMCN should restructure and enrich courses offered by schools of nursing and midwifery to the equivalent standards in postsecondary institutions. The network should affiliate current hospital-based nursing programs to polytechnics for students to gain rigorous academic contents and clinical skills for professional proficiency. Finally, the NMCN should articulate its position on the benefits of APNs as doctor substitutes in the health system, especially at the primary healthcare level and use it to make a case for the introduction of APN.

\section{Conclusion}

This study shows that there is a need for APN because most nurses and midwives in the study already perform advanced functions that align with the scope of practice, standards, and competences of APN recommended by the International Council of Nurses (2008). The absence of doctors in primary health delivery and the increasing number of patients with different health needs impose compelling circumstances on nurses and midwives to perform advanced duties. Under such prevailing circumstances, and with the fact that many nurses and midwives may be working in a community for a long time, every patient's case becomes personal to them. As a result, they are desirous of a visible pathway to advance their careers to be professionally relevant and responsive to the needs of the communities they serve.

With such situations being common in Nigeria, there is a need to delegate some doctor duties to nurses and midwives who are well trained to make the right judgement in diagnosing and performing procedures in patients' care. APN is a sure pathway to advance the nursing and midwifery profession, as it will also encourage more men into the profession that is gender stereotyped and contribute to its bargaining power in wages and status. Additionally, it will boost the professional image of nurses and midwives, encourage their productivity, and improve their efficiency and access to primary health delivery. Current policies should be revised to grant registered nurses and midwives relevant advanced training opportunities, prescriptive authority, and more work autonomy. APN in Nigeria will reform the health system and enhance the nation's health workforce and capacity for a sustainable health system that will promote health and wellness of the Nigerian population.

\section{References}

Alenoghena, I., Aigbiremolen, A. O., Abejehah, C., \& Eboreime, E. (2014). Primary health care in Nigeria: Strategies and constraints in implementation. International Journal of Community Research, 3, 74-79.

Amangabara, G. T. (2012). Analysis of selected failed gully erosion control works in Imo State. Hydrology for Disaster Management, 2012, 279-287.

Babbie, E. (2016). The practice of social research (14th ed.). Belmont, CA: Wadsworth.

Canadian Institute for Health Information. (2017). Regulated nurses: 2017 data tables [Data file]. Retrieved from https://www.cihi.ca/en/access-data-and-reports

Charmaz, K. (2006). Constructing grounded theory: A practical guide through qualitative analysis. Thousand Oaks, CA: Sage. 
Chimezie, R. O. (2013). A case study of primary healthcare in Isu, Nigeria. (Doctoral dissertation). School of Public Health, Walden University, Minneapolis, MN. Retrieved from https://scholarworks.waldenu.edu/dissertations/1057/

Chimezie, R. O. (2015). Primary healthcare in Nigeria: Overview, challenges, and prospects. Denver, CO: Outskirt Press.

Colombo, F. (2016). The nursing workforce: Past trends, future developments. Retrieved from http://www.oecd.org/health/workforce.htm

Creswell, J. W., \& Cheryl, N. P. (2016). Qualitative inquiry and research design: Choosing from five approaches. Thousand Oaks, CA: Sage.

De-Geesta, S., Moonsa, P., Callensa, B., Guta, C., Lindpaintnera, L., \& Spiriga, R. (2008). Introducing advanced practice nurses/nurse practitioners in health care systems: A framework for reflection and analysis. Swiss Medical Weekly, 138, 621-628.

East, L. A., Arudo, J., Loefler, M., \& Evans, C. M. (2014). Exploring the potential for advanced nursing practice role development in Kenya: A qualitative study. BMC Nursing, 13, 33. doi:10.1186/s12912-014-0033-y

Ekanade, O. V. (2014). The dynamics of forced neoliberalism in Nigeria since the 1980s. Journal of Retracing Africa, 1, 1-24. Retrieved from https://encompass.eku.edu/jora/vol1/iss 1/1

Fox-Mcloy, H. (2014). Interest in advanced practice nursing in Nigeria. Retrieved from https://international.aAPN.org/Content/docs/Nigeria.pdf

Health Resources and Services Administration. (2013). Projecting the supply and demand for primary care practitioners through 2020. Retrieved from https://bhw.hrsa.gov/healthworkforce-analysis/primary-care-2020

Imo State Government. (2019). Imo State: Imo at a glance. Retrieved from https://imostate.gov.ng/

Institute of Medicine. (2011). The future of nursing: Leading the change, advancing health. Washington, DC: National Academies Press.

International Council of Nurses. (2008). The scope of practice, standards, and competencies of the Advanced Practice Nurse. Geneva, Switzerland: Author.

International Council of Nurses Nurse Practitioner/Advanced Practice Nursing Network. (2019). Definition and characteristics of the role. Retrieved from http://international.aAPN.org/Practice/APNRoles

Kaiser Family Foundation. (2015). Nurse practitioner scope of practice laws. Retrieved from https://www.kff.org/other/state-indicator/total-nurse-practitioners/

Madubuko, G. (n.d.). Nurse practitioner/advanced nursing practice development in West Africa: A proposal. Retrieved from https://international.aAPN.org/Content/docs/WestAfrica.pdf

Naylor, M. D., \& Kurtzman, E. T. (2010). The role of nurse practitioners in reinventing primary care. Health Affairs, 29, 5. doi:10.1377/hltaff.2010.0440

New Zealand Ministry of Health. (2017). Nurse Practitioners in New Zealand [Factsheet]. Retrieved from https://www.health.govt.nz/our-work/nursing/nurses-new-zealand/nurse-practitionersnew-zealand

Nwagbara, E. N. (2011). The story of Structural Adjustment Programme in Nigeria from the perspective of the organized labour. Australian Journal of Business and Management Research, 1, 30-41. 
Odili, P. (2019, September 29). Neo-liberalism is the bane of Nigeria. The Nigerian Guardian. Retried from https://www.vanguardngr.com/2019/09/neoliberalism-is-the-bane-of-nigeria/

Okpani, A. I., \& Abimbola, S. (2015). Operationalizing universal health coverage in Nigeria through social health insurance. Nigerian Medical Journal, 56, 305-310. doi:10.4103/03001652.170382

Olorode, O. (2016, September 6). Thirty years of neoliberalism in Nigeria: Reform or revolution? Presentation at Reform or Revolution, the symposium of the Academic Staff Union of Universities, Lagos Branch, Nigeria. Retrieved from http://repository.unilag.edu.ng:8080/xmlui/bitstream/handle/123456789/1016/Thirty\%20Year s\%20of\%20Neoliberalism\%20in\%20Nigeria\%20Reform\%20or\%20Revolution.pdf?sequence=1 \&isAllowed=y

Onwuegbuzie, A. J., \& Leech, A. N. (2007). Sampling designs in qualitative research: Making the sampling process more public. The Qualitative Report, 12, 238-254. Retrieved from http://www.nova.edu/ssss/QR/QR12-2/onwuegbuzie1.pdf

Pulcini, J., Jelic, M., Gul, R., \& Loke, A. Y. (2010). An international survey on advanced practice nursing education, practice, and regulation. Journal of Nursing Scholarship, 42, 31-39. doi:10.1111/j.1547-5069.2009.01322.x

Royal College of General Practitioners. (2015). General practice: Advanced nurse practitioner competencies. Retrieved from http://www.rcgp.org.uk/policy/rcgp-policy-areas/nursing.aspx

Sheer, B., Kam, F., \& Wong, Y. (2008). The development of advanced nursing practice globally. Journal of Nursing Scholarship, 40, 204-211.

Sibbald, B., Laurant, M. G., \& Reeves, D. (2006). Advanced nurse roles in U.K. primary care. The Medical Journal of Australia, 185, 10-12.

United States Agency for International Development. (2019). Nigeria: Global health. Retrieved from https://www.usaid.gov/nigeria/global-health

U.S. Central Intelligence Agency. (2019). World factbook: Africa: Nigeria. Retrieved from https://www.cia.gov/library/publications/the-world-factbook/geos/ni.html

Welcome M. O. (2011). The Nigerian health care system: Need for integrating adequate medical intelligence and surveillance systems. Journal of Pharmacy \& Bioallied Sciences, 3, 470-478. doi:10.4103/0975-7406.90100

World Bank. (2019). Current health expenditure (\% of GDP). Retrieved from https://data.worldbank.org/indicator/SH.XPD.CHEX.GD.ZS

World Health Organization. (2011). The Abuja declaration: Ten years on. Retrieved from https://www.who.int/healthsystems/publications/abuja_report_aug_2011.pdf?ua=1

The Journal of Social Change, sponsored by Walden University, welcomes manuscripts focusing on interdisciplinary research in social change that improves the human condition and moves people, groups, organizations, cultures, and society toward a more positive future.

Walden University Publishing: http://www.publishing.waldenu.edu 